Original paper

\title{
3D image-based dosimetry for Yttrium-90 radioembolization of hepatocellular carcinoma: Impact of imaging method on absorbed dose estimates
}

\author{
Julia Brosch $^{\text {a, }}$, Astrid Gosewisch ${ }^{a}$, Lena Kaiser ${ }^{a}$, Max Seidensticker ${ }^{b}$, Jens Ricke ${ }^{\mathrm{b}}$, \\ Johannes Zellmer ${ }^{a}$, Peter Bartenstein ${ }^{a}$, Sibylle Ziegler ${ }^{a}$, Harun Ilhan ${ }^{a}$, Andrei Todica ${ }^{a}$, \\ Guido Böning ${ }^{\text {a,* }}$
}

${ }^{\text {a }}$ Department of Nuclear Medicine, University Hospital, Ludwig-Maximilians-University Munich, Munich, Germany

${ }^{\mathrm{b}}$ Department of Radiology, University Hospital, Ludwig-Maximilians-University Munich, Munich, Germany

\section{A R T I C L E I N F O}

\section{Keywords:}

Radioembolization

SIRT

Yttrium-90

Dosimetry

Yttrium-90 PET

Bremsstrahlung SPECT

\begin{abstract}
A B S T R A C T
Background: To improve therapy outcome of Yttrium-90 selective internal radiation therapy $\left({ }^{90} \mathrm{Y}\right.$ SIRT), patientspecific post-therapeutic dosimetry is required. For this purpose, various dosimetric approaches based on different available imaging data have been reported. The aim of this work was to compare post-therapeutic 3D absorbed dose images using Technetium-99m $\left({ }^{99 \mathrm{~m}} \mathrm{Tc}\right)$ MAA SPECT/CT, Yttrium-90 $\left({ }^{90} \mathrm{Y}\right)$ bremsstrahlung (BRS) SPECT/CT, and ${ }^{90} \mathrm{Y}$ PET/CT.

Methods: Ten SIRTs of nine patients with unresectable hepatocellular carcinoma (HCC) were investigated. The ${ }^{99 \mathrm{~m}}$ Tc SPECT/CT data, obtained from ${ }^{99 \mathrm{~m}}$ Tc-MAA-based treatment simulation prior to ${ }^{90}$ Y SIRT, were scaled with the administered ${ }^{90} \mathrm{Y}$ therapy activity. 3D absorbed dose images were generated by dose kernel convolution with scaled ${ }^{99 \mathrm{~m}} \mathrm{Tc} /{ }^{90} \mathrm{Y}$ SPECT/CT, ${ }^{90} \mathrm{Y}$ BRS SPECT/CT, and ${ }^{90} \mathrm{Y}$ PET/CT data of each patient. Absorbed dose estimates in tumor and healthy liver tissue obtained using the two SPECT/CT methods were compared against ${ }^{90} \mathrm{Y}$ PET/CT. Results: The percentage deviation of tumor absorbed dose estimates from ${ }^{90} \mathrm{Y}$ PET/CT values was on average -2 $\pm 18 \%$ for scaled ${ }^{99 \mathrm{~m}} \mathrm{Tc} /{ }^{90} \mathrm{Y}$ SPECT/CT, whereas estimates from ${ }^{90} \mathrm{Y}$ BRS SPECT/CT differed on average by -50 $\pm 13 \%$. For healthy liver absorbed dose estimates, all three imaging methods revealed comparable values. Conclusion: The quantification capabilities of the imaging data influence ${ }^{90} \mathrm{Y}$ SIRT tumor dosimetry, while healthy liver absorbed dose values were comparable for all investigated imaging data. When no ${ }^{90} \mathrm{Y}$ PET/CT image data are available, the proposed scaled ${ }^{99 \mathrm{~m}} \mathrm{Tc} /{ }^{90} \mathrm{Y}$ SPECT/CT dosimetry method was found to be more appropriate for HCC tumor dosimetry than ${ }^{90} \mathrm{Y}$ BRS SPECT/CT based dosimetry.
\end{abstract}

\section{Background}

Yttrium-90 selective internal radiation therapy (SIRT) became an established treatment option for hepatocellular carcinoma (HCC) and many other liver tumor entities [1]. To ensure safe delivery of the ${ }^{90} \mathrm{Y}$ microspheres with limited shunt to the lung and extra-hepatic regions, a treatment simulation with Technetium-99m-labeled macroaggregated albumin $\left({ }^{99 \mathrm{~m}} \mathrm{Tc}-\mathrm{MAA}\right)$ followed by a planar gamma camera image and a SPECT/CT scan is performed prior to therapy [2]. Patient-individual planning of absorbed dose for ${ }^{90} \mathrm{Y}$ SIRT is performed in a majority of centers [3]. But although the European council directive 2013/59/ Euratom emphasizes the need of patient-individual absorbed dose verification [4], post-therapeutic ${ }^{90} \mathrm{Y}$ dosimetry is not yet part of the clinical routine [5].

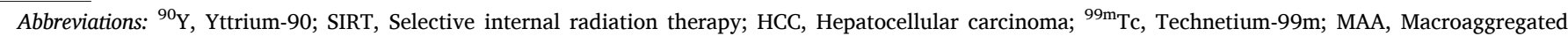

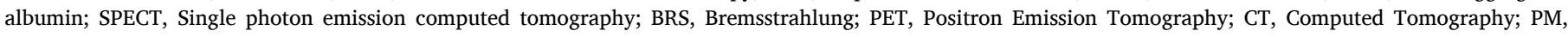

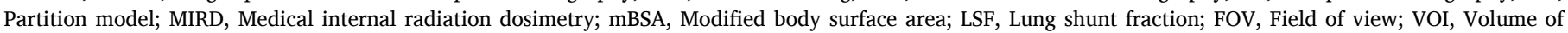

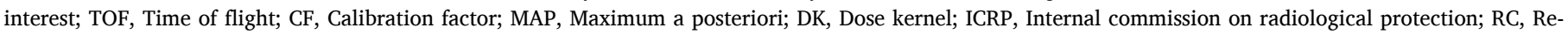
covery coefficient; SNR, Signal-to-noise ratio.

* Corresponding authors at: Department of Nuclear Medicine, University Hospital, LMU Munich, Marchioninistrasse 15, 81377 Munich, Germany.

E-mail address: Julia.Brosch@med.uni-muenchen.de (J. Brosch). 
For patient individualized therapy with improved therapy outcome as well as for a safe administration of further treatment cycles, an individualized dosimetry for tumor and healthy liver parenchyma after ${ }^{90} \mathrm{Y}$ SIRT is advisable [6].

In this regard, ${ }^{90} \mathrm{Y}$ bremsstrahlung (BRS) SPECT/CT imaging has been the method of choice for visual post-therapeutic treatment verification. While ${ }^{90} \mathrm{Y}$ PET/CT imaging gained increasing importance over the past few years [7], this method is still less established and available in clinical routine. Although ${ }^{90} \mathrm{Y}$ PET imaging is affected by the low branching ratio of ${ }^{90} \mathrm{Y}$ for internal pair production of $(31.86 \pm 0.47) \times$ $10^{-6}$ [8], several phantom studies addressing the optimal ${ }^{90} \mathrm{Y}$ PET imaging and reconstruction parameters have shown the feasibility of ${ }^{90} \mathrm{Y}$ PET $[9,10]$. Others investigated the optimal ${ }^{90} \mathrm{Y}$ BRS imaging parameter choice and reconstruction methods $[11,12]$, and deduced that ${ }^{90} \mathrm{Y}$ BRS SPECT imaging is still less capable of correctly quantifying activity distributions due to the significantly large electron range, the continuous nature of the bremsstrahlung spectrum and the lack of a discrete photopeak suitable for imaging. Yue et al. and Elschot et al. further investigated the quantification accuracies of ${ }^{90} \mathrm{Y}$ BRS SPECT/CT and ${ }^{90} \mathrm{Y}$ PET/CT for dosimetry purposes using phantom measurements [13,14] and concluded that the quantification accuracy of ${ }^{90} \mathrm{Y}$ PET is superior to ${ }^{90} \mathrm{Y}$ BRS SPECT. However, up to now no standardized clinical scan protocol, neither for ${ }^{90} \mathrm{Y}$ PET/CT nor ${ }^{90} \mathrm{Y}$ BRS SPECT/CT, has been defined. Therefore, inter-center comparability of image based ${ }^{90} \mathrm{Y}$ dosimetry is limited, independent of the various existing dosimetric calculation methods [15].

Pre-therapeutic absorbed dose estimation in ${ }^{90} \mathrm{Y}$ SIRT is often performed based on ${ }^{99 \mathrm{~m}} \mathrm{Tc}$-MAA SPECT/CT imaging, relying either on the partition model (PM) or on the tumor and organ S-value based dosimetry as described by the medical internal radiation dosimetry (MIRD) formalism [16-21]. A drawback of these methods is the related assumption of a homogeneously distributed activity within the liver, which neglects the patient-individual ${ }^{90} \mathrm{Y}$ microsphere distribution. These approaches consequently show a limited applicability in SIRT dosimetry, only being suitable for estimating an overall mean absorbed dose for either tumorous or healthy liver parenchyma. A few studies have already addressed alternative methods for 3D dosimetry for ${ }^{90} \mathrm{Y}$ SIRT based on ${ }^{99 \mathrm{~m}}$ Tc-MAA SPECT/CT [22-24]. However, Ulrich et al., Wondergem et al., and Knešaurek et al. were critical about the comparability of uptake patterns from pre-therapeutic ${ }^{99 \mathrm{~m}}$ Tc-MAA SPECT/CT and post-therapeutic ${ }^{90} \mathrm{Y}$ microsphere imaging [25-27]. Additionally, several groups investigated post-therapeutic 3D dosimetry methods using ${ }^{90} \mathrm{Y}$ BRS SPECT/CT or ${ }^{90} \mathrm{Y}$ PET/CT [9,28-30].

It can be summarized that each of the different processing strategies and associated imaging methods for ${ }^{90} \mathrm{Y}$ SIRT dosimetry has its individual limitations. Consequently, no standard methodology for ${ }^{90} \mathrm{Y}$ SIRT related imaging and image processing has been established so far [15]. The aim of this study was therefore to assess the comparability of the absorbed dose estimates of tumorous and healthy liver tissue and to quantify differences in dependence of the available imaging method, namely ${ }^{99 \mathrm{~m}} \mathrm{Tc}$-MAA SPECT/CT and ${ }^{90} \mathrm{Y}$ BRS SPECT/CT in comparison to ${ }^{90} \mathrm{Y} \mathrm{PET} / \mathrm{CT}$.

\section{Material and methods}

\subsection{Phantom measurements}

To enable a better interpretation of the absorbed dose estimates obtained from ${ }^{99 \mathrm{~m}} \mathrm{Tc}$-MAA SPECT/CT, ${ }^{90} \mathrm{Y}$ BRS SPECT/CT and ${ }^{90} \mathrm{Y}$ PET/ $\mathrm{CT}$, the capability to quantify known activity concentrations of each imaging procedure was determined by phantom measurements. For this purpose, a NEMA IEC Body Phantom ${ }^{\text {TM }}$ with six fillable spheres (inner diameters: $10 \mathrm{~mm}, 13 \mathrm{~mm}, 17 \mathrm{~mm}, 22 \mathrm{~mm}, 28 \mathrm{~mm}, 37 \mathrm{~mm}$ ) was filled with a sphere to background activity concentration ratio of $8: 1$. The total ${ }^{99 \mathrm{~m}} \mathrm{Tc}$ phantom activity was $495.6 \mathrm{MBq}$ and was defined such that the activity concentration in the phantom background corresponds to an average activity concentration in the liver of exemplary patients receiving ${ }^{99 \mathrm{~m}} \mathrm{Tc}$-MAA. The total ${ }^{90} \mathrm{Y}$ phantom activity was $1.88 \mathrm{GBq}$ of ${ }^{90} \mathrm{Y}$ chloride with added DTPA to avoid sticking to the phantom walls and to mimic typical maximum ${ }^{90} \mathrm{Y}$ SIRT activities in our institution. The ${ }^{99 \mathrm{~m}} \mathrm{Tc}$ SPECT/CT, ${ }^{90} \mathrm{Y}$ BRS SPECT/CT and ${ }^{90} \mathrm{Y}$ PET/CT acquisition and reconstruction parameters were in concordance with the corresponding routine clinical patient protocols, which are described in the following sections. Spherical volumes of interest (VOIs) with a diameter according to the phantom specifications were placed on the accompanying CT image, and a box-shaped VOI with $1700 \mathrm{ml}$ volume was placed in the phantom background. The recovery coefficients (RC) for spheres and the phantom background were determined according to equation (1) by dividing the average activity concentrations of the spheres and background in the corresponding image by the known activity concentration,

$\mathrm{RC}=\frac{\mathrm{C}_{\text {image }}}{\mathrm{C}_{\text {known }}} \cdot 100$

with $\mathrm{RC}$ being the recovery coefficient, $\mathrm{C}_{\text {image }}$ the activity concentration in $\mathrm{Bq} / \mathrm{ml}$ obtained from the reconstructed image, and $\mathrm{C}_{\text {known }}$ the known activity concentration in $\mathrm{Bq} / \mathrm{ml}$ in the phantom. The signal-tonoise ratios (SNR) of the images were calculated by dividing the difference of the activity concentrations in the sphere VOIs and the background VOI by the standard deviation in the background VOI, as given by equation (2) [31],

$\mathrm{SNR}=\frac{\mathrm{C}_{\text {sphere }}-\mathrm{C}_{\text {background }}}{\sigma_{\text {background }}}$

with SNR being the signal-to-noise ratio, $\mathrm{C}_{\text {sphere }}$ the activity concentration in $\mathrm{Bq} / \mathrm{ml}$ per sphere VOI, $\mathrm{C}_{\text {background }}$ the activity concentration in $\mathrm{Bq} / \mathrm{ml}$ in the background VOI, and $\sigma_{\text {background }}$ the standard deviation of the background VOI in $\mathrm{Bq} / \mathrm{ml}$.

\subsection{Patient selection, therapy procedure and image acquisition}

\subsubsection{Patient selection}

This study was conducted retrospectively on anonymized data from ten SIR-therapies of nine patients suffering from hepatocellular carcinoma (HCC). The study protocol was approved by the local ethics committee. Written informed consent was obtained from all patients. Patients underwent radioembolization with Yttrium-90-labeled resin microspheres (SIR-Spheres, Sirtex Medical Ltd., Australia) as a lobar or sequential lobar treatment under fluoroscopic guidance. MR-imaging with a liver specific contrast agent was performed before therapy and treatment simulation. All patients received a treatment simulation with ${ }^{99 m}$ Tc-MAA followed by planar scintigraphy of the thorax and the abdomen to quantify the liver to lung shunt fraction (LSF) and a SPECT/ CT of the abdominal area to exclude extra-hepatic tracer accumulation. The ${ }^{90} \mathrm{Y}$ therapy activity was either determined using the modified body surface area (mBSA) method or the partition model (PM) with the aim to deliver at least $120 \mathrm{~Gy}$ to the tumor while keeping the absorbed dose to the healthy liver tissue considerably low between 40 and $60 \mathrm{~Gy}$ depending on the patient's liver function $[2,16]$. Patient characteristics and corresponding therapy activities are summarized in table 1. For post-therapeutic treatment verification, a ${ }^{90} \mathrm{Y}$ BRS SPECT/CT scan and a ${ }^{90} \mathrm{Y}$ PET/CT scan were acquired.

\subsubsection{Image acquisition and reconstruction}

2.2.2.1. ${ }^{99 m}$ Tc-MAA-SPECT/CT. Within 1.5 h post injection of ${ }^{99 \mathrm{~m}} \mathrm{Tc}$ MAA into the (right and/or left) hepatic artery according to the planned catheter position for radioembolization, the patients were examined on a dual-head Symbia T2 SPECT/CT (Siemens Healthcare, Germany) with a low-energy-high-resolution collimator. SPECT projections were acquired with an energy window centered at the ${ }^{99 \mathrm{~m}} \mathrm{Tc}$ photopeak of 140 $\mathrm{keV}( \pm 7.5 \%)$ and with an additional scatter window at $115 \mathrm{keV}( \pm 10 \%)$ 
Table 1

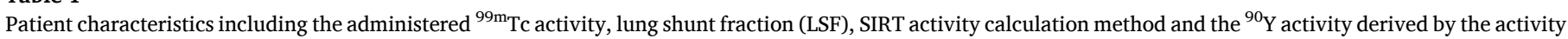
in the FOV of the ${ }^{90} \mathrm{Y}$ PET image. One lesion was evaluated per SIR-therapy.

\begin{tabular}{|c|c|c|c|c|c|c|c|c|}
\hline Patient no. & Age & $\operatorname{Sex}[\mathrm{m} / \mathrm{f}]$ & ${ }^{99 m}$ Tc activity [MBq] & LSF [\%] & ${ }^{90} \mathrm{Y}$ SIRT activity calculation & ${ }^{90} \mathrm{Y}$ activity $[\mathrm{MBq}]$ & Treated liver volume $[\mathrm{ml}]$ & Tumor volume $[\mathrm{ml}]$ \\
\hline 1 & 71 & $\mathrm{~m}$ & 99 & 9.6 & mBSA & 1266 & 2135 & 1162 \\
\hline 2 & 79 & $\mathrm{~m}$ & 91 & 7.7 & PM & 2431 & 2093 & 1760 \\
\hline 3 & 65 & $\mathrm{~m}$ & 62 & 4.1 & $\mathrm{PM}$ & 1110 & 687 & 514 \\
\hline 4 & 77 & $\mathrm{~m}$ & 88 & 5.0 & mBSA & 1224 & 820 & 55 \\
\hline 5 & 64 & $\mathrm{~m}$ & 94 & 4.8 & mBSA & 1046 & 232 & 129 \\
\hline 6 & 36 & $\mathrm{f}$ & 74 & 4.3 & $\mathrm{PM}$ & 1807 & 922 & 389 \\
\hline 7 & 48 & $\mathrm{f}$ & 94 & 2.4 & mBSA & 718 & 533 & 37 \\
\hline 8 - SIRT 1 & 65 & $\mathrm{~m}$ & 105 & 5.3 & $\mathrm{PM}$ & 735 & 692 & 50 \\
\hline 8 - SIRT 2 & & & & & $\mathrm{PM}$ & 547 & 197 & 16 \\
\hline 9 & 81 & $\mathrm{f}$ & 87 & 3.8 & $\mathrm{PM}$ & 1295 & 2135 & 400 \\
\hline
\end{tabular}

in a $128 \times 128$ matrix with 32 angular steps per head with 25 s per step [2]. Quantitative SPECT reconstruction was performed (5 MAP iterations, 16 subsets, penalty of 0.001 , collimator-specific depth-dependent detector response, voxel size $\left.(4.7952 \mathrm{~mm})^{3}\right)$ [32] using the corresponding low dose CT (voxel size $0.9766 \times 0.9766 \times 5.0 \mathrm{~mm}^{3}$ ) for attenuation correction and the dual energy window method for scatter correction. A previously determined nuclide-, collimator- and cameraspecific calibration factor, derived from a cylindrical phantom, was used for converting the measured counts per second per voxel to Becquerel per milliliter.

2.2.2.2. ${ }^{90} Y$ BRS SPECT/CT. The ${ }^{90} \mathrm{Y}$ BRS SPECT/CT data were acquired within $24 \mathrm{~h}$ post SIR-therapy using the same camera as has been utilized for the ${ }^{99 \mathrm{~m}}$ Tc-MAA SPECT/CT, equipped with a medium-energylow-penetration collimator. As proposed by Siman et al. [33], a primary energy window was set at $108 \mathrm{keV}( \pm 20 \%)$ and a background energy window at $360 \mathrm{keV}( \pm 15 \%)$. Projections were recorded in a $128 \times 128$ matrix with 32 angular steps per head with a duration of 40 s per step. SPECT reconstruction (15 MAP iterations, 16 subsets, penalty of 0.01 , voxel size $\left.(4.7952 \mathrm{~mm})^{3}\right)$ used the low dose CT (voxel size $0.9766 \times$ $0.9766 \times 5.0 \mathrm{~mm}^{3}$ ) to account for attenuation in the primary energy window and included the background compensation method proposed by Siman et al. [33] using the background energy window. This approach was considered as a good compromise for semi-quantitative ${ }^{90} \mathrm{Y}$ BRS imaging, since appropriate modelling of electron transport and bremsstrahlung production as well as detector and collimator response for bremsstrahlung radiation in ${ }^{90} \mathrm{Y}$ BRS SPECT/CT image reconstruction is not yet available. Consequently, we observed a spacevariant and object-dependent relation between reconstructed counts per second per voxel and true activity. Based on the assumptions that the majority of the administered activity remained stationary in the liver and that the entire liver was contained within the field of view (FOV) of the ${ }^{90} \mathrm{Y}$ BRS SPECT/CT volume, we performed a self-calibration of each reconstructed ${ }^{90} \mathrm{Y}$ BRS SPECT/CT study. The individual calibration factor (CF) was obtained by dividing the decay corrected ${ }^{90} \mathrm{Y}$ therapy activity obtained from ${ }^{90} \mathrm{Y}$ PET FOV by the sum of reconstructed counts per second in the entire ${ }^{90} \mathrm{Y}$ BRS SPECT/CT FOV volume and by the related voxel volume to obtain Becquerel per milliliter [34].

2.2.2.3. ${ }^{90} Y$ PET/CT. All patients received a ${ }^{90} \mathrm{Y}$ time-of-flight (TOF) PET/CT acquisition (Biograph mCT flow, VG60A, Siemens Healthcare, Germany) of the liver within $24 \mathrm{~h}$ post SIR-therapy in flow mode using a table scan speed of $0.2 \mathrm{~mm} / \mathrm{s}$ [35] and a low dose CT (voxel size 1.5234 $\times 1.5234 \times 3.0 \mathrm{~mm}^{3}$ ). The radioisotope ${ }^{90} \mathrm{Y}$ was selected for acquisition and Siemens TrueX TOF image reconstruction was performed with 2 iterations and 21 subsets in a $128 \times 128$ matrix (voxel size $6.3638 \times$ $6.3638 \times 3.0 \mathrm{~mm}^{3}$ ) with a $10 \mathrm{~mm}$ FWHM post-reconstruction Gaussian filter.

2.2.2.4. Image processing. The ${ }^{90} \mathrm{Y}$ BRS SPECT/CT, ${ }^{90} \mathrm{Y}$ PET/CT and corresponding $\mathrm{MR}$ image were all co-registered with a rigid registration method and sampled to the CT voxel size of $0.9766 \times 0.9766 \times 5.0 \mathrm{~mm}^{3}$ of the ${ }^{99 \mathrm{~m}}$ Tc-MAA SPECT/CT scan with PMOD (v4.003; PMOD Technologies LLC). The total administered ${ }^{99 \mathrm{~m}}$ Tc activity was derived by calculating the sum of activity values over all voxels over the entire SPECT FOV from the calibrated ${ }^{99 \mathrm{~m}}$ Tc-MAA SPECT/CT. Similarly, the administered ${ }^{90} \mathrm{Y}$ activity was obtained from the decay corrected sum of the activity values per voxel over all voxels in the entire PET FOV. We decided to use this approach to provide a similar basic procedure for all investigated patients, because for the radioembolization procedure in our institution it is possible that occasionally not the full amount of prescribed ${ }^{90} \mathrm{Y}$-SIR-Spheres is administered for patient safety reasons and to prevent flow stasis $[5,15]$. Moreover, with the dose calibrator response being very sensitive to changes in the volume [36] and geometry [37] for ${ }^{90} \mathrm{Y}$, it becomes difficult to accurately measure the ${ }^{90} \mathrm{Y}$ residual activity in the vial and tubes of the application system in the dose calibrator. In contrast, the reproducibility of the estimated ${ }^{90} \mathrm{Y}$ therapy activity by the total FOV activity of the PET/CT device has been shown by Carlier et al. [38] with a proportionality coefficient of $1.04 \pm$ 0.02 .

\subsection{Dosimetry calculation}

\subsubsection{Generation of absorbed dose images}

Based on the assumptions that the ${ }^{90} \mathrm{Y}$ SIR-Spheres are trapped in the liver tissue and that due to the embolization effect no sphere migration occurs during SIRT and post-therapeutic imaging [5], a single image at one time point was considered to be sufficient for dosimetric estimations in SIRT. In our institution, the treatment simulation with ${ }^{99 \mathrm{~m}} \mathrm{Tc}-\mathrm{MAA}$ is performed in a single procedure with application of ${ }^{99 \mathrm{~m}} \mathrm{Tc}$-MAA according to the planned catheter position or positions of the subsequent SIRTs in a lobar or sequential setting. Thus, the actual treated volume in each SIRT had to be detected. For each of the sequential SIRTs, this treated liver volume was determined by applying a $10 \%$ iso-contour VOI on the corresponding post-therapeutic ${ }^{90} \mathrm{Y}$ BRS SPECT volume. This threshold was determined with the ${ }^{90} \mathrm{Y}$ BRS SPECT/CT phantom image and provided a reproducible delineation of the treated liver volume at ${ }^{90} \mathrm{Y}$ SIRT. It was in good agreement with the treated liver lobe or liver segment, when displayed with the corresponding CT and MR images as verified by an experienced nuclear medicine physician. The quantitative whole liver ${ }^{99 \mathrm{~m}}$ Tc-MAA SPECT/CT was divided by the total administered ${ }^{99 \mathrm{~m}} \mathrm{Tc}$ activity and then scaled with the total administered ${ }^{90} \mathrm{Y}$ therapy activity within the treated liver volume VOI using an in-house developed MATLAB code (R2018b; The MathWorks, Inc. Natick, MA), similar to the normalization approach by Kafrouni et al. [39]. Outside the VOI of the treated liver volume, the image contents were set to zero. The resulting scaled ${ }^{99 \mathrm{~m}} \mathrm{Tc} /{ }^{90} \mathrm{Y}$ activity image consequently represented the pre-therapeutic distribution pattern of ${ }^{99 \mathrm{~m}}$ Tc-MAA as well as the total administered therapeutic ${ }^{90} \mathrm{Y}$ activity and was considered as a surrogate for the local ${ }^{90} \mathrm{Y}$ distribution. Assuming no redistribution of activity after administration, the time-integrated activity images were obtained by dividing each of the three activity images - scaled 
${ }^{99 \mathrm{~m}} \mathrm{Tc} /{ }^{90} \mathrm{Y}$ SPECT/CT based, ${ }^{90} \mathrm{Y}$ BRS SPECT/CT based and ${ }^{90} \mathrm{Y}$ PET/CT based - by the decay constant of ${ }^{90} \mathrm{Y}[40]$. 3D absorbed dose images were generated by convolving these time-integrated activity images with a 3D ${ }^{90} \mathrm{Y}$ absorbed dose kernel which was derived by Monte Carlo simulations (FLUKA Monte Carlo code [41]) for ICRP soft tissue.

\subsubsection{Tumor and healthy liver mean absorbed doses}

The tumor was manually delineated on the pre-therapeutic MR image using PMOD (v4.003; PMOD Technologies LLC). This tumor VOI was then copied to the scaled ${ }^{99 \mathrm{~m}_{\mathrm{Tc}}}{ }^{90} \mathrm{Y}$ SPECT/CT based, ${ }^{90} \mathrm{Y}$ BRS SPECT/CT based, and ${ }^{90} \mathrm{Y}$ PET/CT based absorbed dose images to determine the corresponding estimates of mean tumor absorbed doses. To allow the assessment of the absorbed dose estimates to the healthy liver tissue, a healthy liver VOI was derived by subtracting the tumor VOI from the treated liver VOI. The mean absorbed dose to the healthy liver tissue was then determined by applying the healthy liver VOI to the scaled ${ }^{99 \mathrm{~m}} \mathrm{Tc} /{ }^{90} \mathrm{Y}$ SPECT/CT based, ${ }^{90} \mathrm{Y}$ BRS SPECT/CT based, and ${ }^{90} \mathrm{Y}$ PET/CT based absorbed dose images. Additionally, the relative percentage deviations with respect to ${ }^{90} \mathrm{Y}$ PET/CT were calculated for the tumor and liver absorbed dose estimates for the scaled ${ }^{99 \mathrm{~m}} \mathrm{Tc} /{ }^{90} \mathrm{Y}$ SPECT/CT and ${ }^{90} \mathrm{Y}$ BRS SPECT/CT. Pearson's correlation and $t$-test for paired samples were conducted with MATLAB and Bland-Altman analysis [42] was performed to compare the obtained absorbed dose estimates.

\subsubsection{D absorbed dose distributions}

The 3D absorbed dose images based on scaled ${ }^{99 \mathrm{~m}} \mathrm{Tc} /{ }^{90} \mathrm{Y} \mathrm{SPECT} / \mathrm{CT}$, ${ }^{90} \mathrm{Y}$ BRS SPECT/CT, and ${ }^{90} \mathrm{Y}$ PET/CT were analyzed quantitatively by assessment of the minimum absorbed doses to $25 \%, 50 \%$ and $75 \%$ (hereafter referred to as D25, D50, D75) of the tumor VOI and healthy liver tissue VOI. D25, D50, and D75 consequently represent the absorbed doses that are at least received in $25 \%, 50 \%$, and $75 \%$ of the VOI volume.

\section{Results}

\subsection{Phantom measurements}

To visualize the difference between the three imaging methods, a transversal slice of the phantom is displayed in Fig. 1 for ${ }^{90} \mathrm{Y}$ BRS SPECT/ $\mathrm{CT},{ }^{99 \mathrm{~m}} \mathrm{Tc}$ SPECT/CT and ${ }^{90} \mathrm{Y}$ PET/CT, each scaled to $80 \%$ of its maximum. The RC and SNR determined by the phantom measurements are shown in Fig. 2 for the four largest sphere diameters. With the investigated imaging methods ${ }^{90} \mathrm{Y}$ BRS SPECT/CT, ${ }^{99 \mathrm{~m}_{\mathrm{Tc}}}$ SPECT/CT and ${ }^{90} \mathrm{Y}$ PET/CT, recovery coefficients of $37 \%, 75 \%$ and $83 \%$ were achieved for the largest sphere ( $37 \mathrm{~mm}$ diameter, $26 \mathrm{ml}$ ), while the corresponding RCs for the background VOI were 101\%, $95 \%$ and $96 \%$.

\subsection{Mean tumor and healthy liver absorbed dose}

\subsubsection{Mean tumor absorbed dose}

The estimated mean tumor absorbed dose for all patients was $81 \pm$
57 Gy for scaled ${ }^{99 \mathrm{~m}} \mathrm{Tc} /{ }^{90} \mathrm{Y}$ SPECT/CT and $88 \pm 50 \mathrm{~Gy}$ for ${ }^{90} \mathrm{Y}$ PET/CT, whereas an overall smaller mean tumor absorbed dose estimate of $41 \pm$ $19 \mathrm{~Gy}$ was obtained from ${ }^{90} \mathrm{Y}$ BRS SPECT/CT. The tumor absorbed dose estimates per patient are given in table 2. This observation is illustrated in Fig. 3 a. The mean percentage difference of tumor absorbed dose estimates compared to ${ }^{90} \mathrm{Y}$ PET/CT was $-2 \pm 18 \%$ (min: $-37 \%$, max: $+23 \%$ ) for scaled ${ }^{99 \mathrm{~m}} \mathrm{Tc} /{ }^{90} \mathrm{Y}$ SPECT/CT and $-50 \pm 13 \%$ (min: $-66 \%$, max: $-16 \%$ ) for ${ }^{90} \mathrm{Y}$ BRS SPECT/CT. Fig. $3 \mathrm{~b}$ shows both SPECT/CT based tumor absorbed dose estimates plotted against those of the ${ }^{90} \mathrm{Y}$ $\mathrm{PET} / \mathrm{CT}$ for each patient. A strong correlation was found between scaled ${ }^{99 \mathrm{~m}} \mathrm{Tc} /{ }^{90} \mathrm{Y} \mathrm{SPECT} / \mathrm{CT}$ and ${ }^{90} \mathrm{Y}$ PET/CT $(\mathrm{r}=0.88, \mathrm{p}=0.29)$, and between ${ }^{90} \mathrm{Y}$ BRS SPECT/CT and ${ }^{90} \mathrm{Y}$ PET/CT based absorbed dose values ( $\mathrm{r}=$ $0.94, \mathrm{p} \ll 0.01$ ). The Bland-Altman plots of tumor absorbed dose estimates from scaled ${ }^{99 \mathrm{~m}} \mathrm{Tc} /{ }^{90} \mathrm{Y}$ SPECT/CT and ${ }^{90} \mathrm{Y}$ BRS SPECT/CT compared to ${ }^{90} \mathrm{Y}$ PET/CT are given in Fig. $4 \mathrm{a}$ and b. Smaller differences in tumor absorbed dose estimates were found for scaled ${ }^{99 \mathrm{~m}} \mathrm{Tc} /{ }^{90} \mathrm{Y}$ SPECT/CT (95\% confidence interval:-32.9 Gy to $47.3 \mathrm{~Gy}$, mean difference: $7.2 \mathrm{~Gy}$ ) than for ${ }^{90} \mathrm{Y}$ BRS SPECT/CT (95\% confidence interval: -4.6 Gy to $98.8 \mathrm{~Gy}$, mean difference: $47.1 \mathrm{~Gy}$ ) compared to ${ }^{90} \mathrm{Y}$ PET/CT based absorbed dose estimates.

\subsubsection{Mean healthy liver absorbed dose}

The mean absorbed dose to the healthy liver tissue was determined to $19 \pm 23 \mathrm{~Gy}, 18 \pm 7 \mathrm{~Gy}$ and $22 \pm 16 \mathrm{~Gy}$ for scaled ${ }^{99 \mathrm{~m}} \mathrm{Tc} /{ }^{90} \mathrm{Y} \mathrm{SPECT} /$ $\mathrm{CT},{ }^{90} \mathrm{Y}$ BRS SPECT/CT and ${ }^{90} \mathrm{Y}$ PET absorbed dose images, respectively. Hence, the mean percentage difference of estimated absorbed dose to healthy liver tissue compared to ${ }^{90} \mathrm{Y}$ PET/CT was $-10 \pm 8 \%$ (min: $-21 \%$, max: $+5 \%$ ) for scaled ${ }^{99 \mathrm{~m}} \mathrm{Tc} /{ }^{90} \mathrm{Y}$ SPECT/CT and $-12 \pm 10 \%$ (min: $-31 \%$, max: $+6 \%$ ) for ${ }^{90} \mathrm{Y}$ BRS SPECT/CT. Table 2 shows healthy liver absorbed dose estimates per patient. In concordance with the observation made for the tumors in the previous section, a strong correlation was found between ${ }^{90} \mathrm{Y}$ BRS SPECT/CT and ${ }^{90} \mathrm{Y}$ PET/CT based absorbed dose values $(\mathrm{r}=0.94, \mathrm{p} \ll 0.01)$, and between scaled ${ }^{99 \mathrm{~m}} \mathrm{Tc} /{ }^{90} \mathrm{Y}$ SPECT $/ \mathrm{CT}$ and ${ }^{90} \mathrm{Y}$ PET/CT based absorbed dose values $(\mathrm{r}=$ $0.98, \mathrm{p} \ll 0.01$ ). The absorbed dose to healthy liver and the correlation of the two SPECT/CT based methods compared to ${ }^{90} \mathrm{Y}$ PET/CT are illustrated in Fig. 5. In Fig. 6, Bland-Altman plots of healthy liver absorbed dose estimates are shown. The absorbed dose differences for healthy liver for scaled ${ }^{99 \mathrm{~m}} \mathrm{Tc} /{ }^{90} \mathrm{Y}$ SPECT/CT (95\% confidence interval:1.2 Gy to $5.5 \mathrm{~Gy}$, mean difference: $2.1 \mathrm{~Gy}$ ) and for ${ }^{90} \mathrm{Y}$ BRS SPECT/CT (95\% confidence interval: $-2.7 \mathrm{~Gy}$ to $8.9 \mathrm{~Gy}$, mean difference: $3.1 \mathrm{~Gy}$ ), each compared with ${ }^{90} \mathrm{Y}$ PET/CT based absorbed dose estimates, showed similar ranges and mean differences.

\section{3. $3 D$ absorbed dose distributions}

Fig. 7 documents exemplarily the 3D absorbed dose images of patient 2 for all three imaging methods, superimposed onto the pre-therapeutic MR image. This Fig. 7 illustrates the overall smaller absorbed dose estimates in ${ }^{90} \mathrm{Y}$ BRS SPECT/CT based absorbed dose images compared to the scaled ${ }^{99 \mathrm{~m}} \mathrm{Tc} /{ }^{90} \mathrm{Y}$ SPECT/CT and ${ }^{90} \mathrm{Y}$ PET/CT based absorbed dose images, which both express comparable intensities in the same

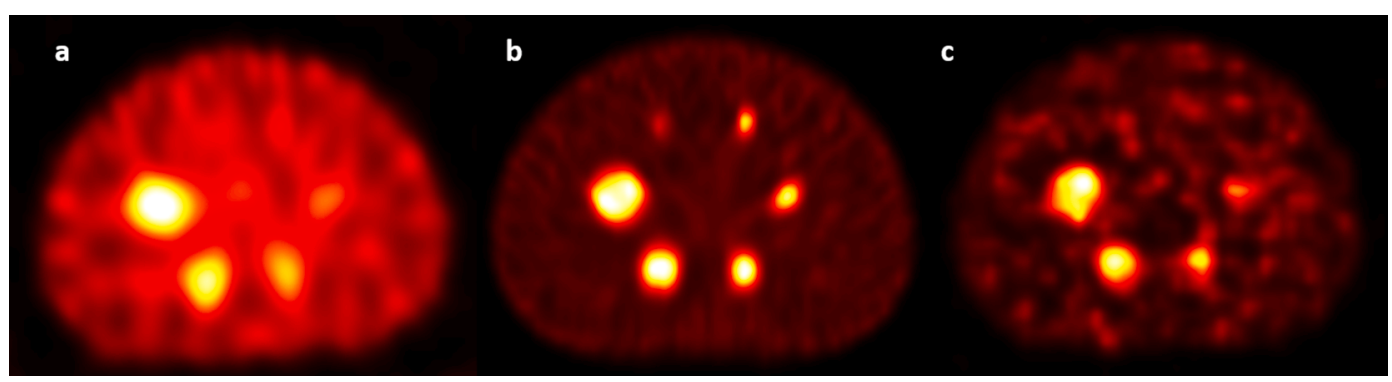

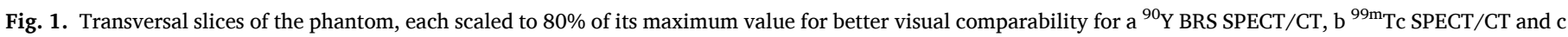
${ }^{90} \mathrm{Y}$ PET/CT. 

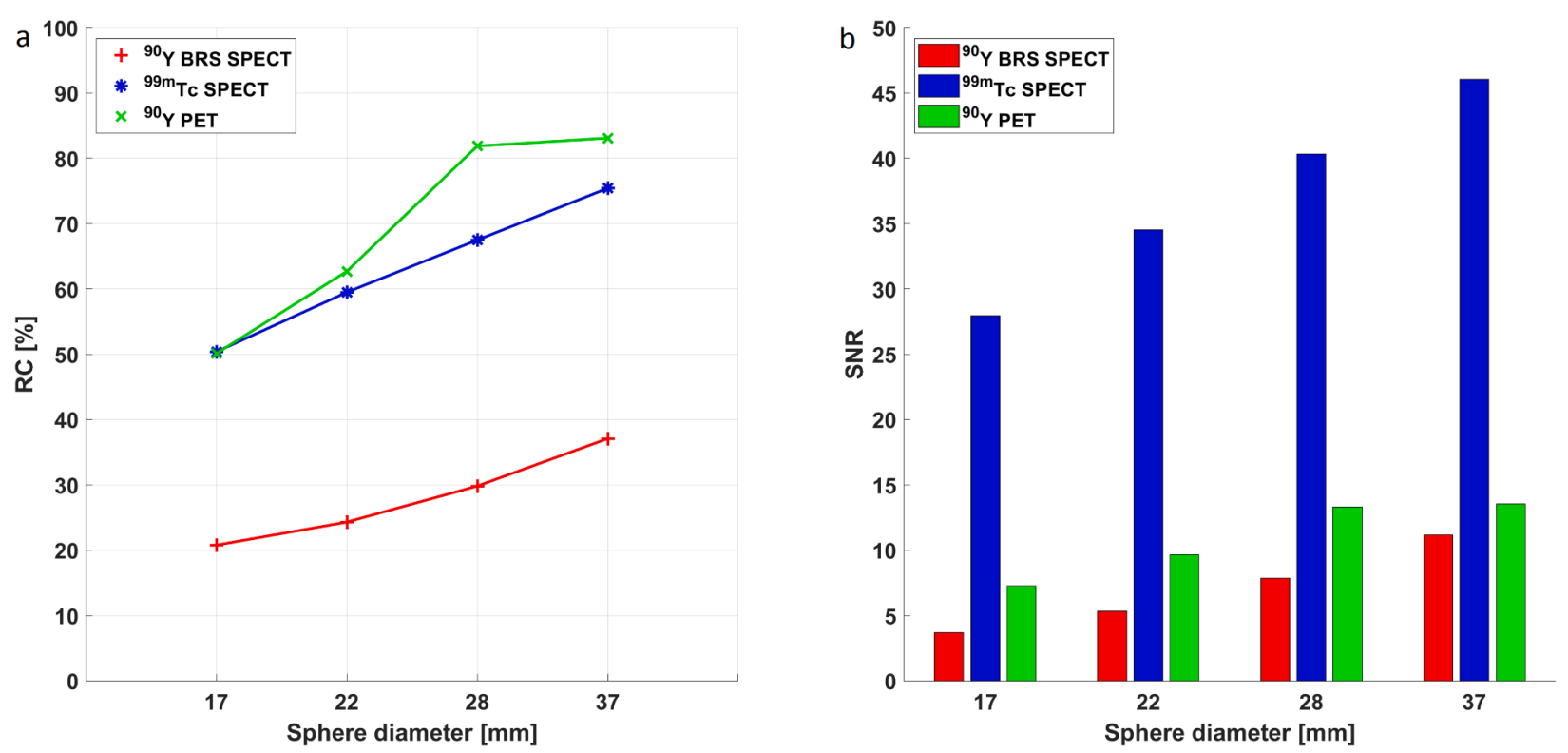

Fig. 2. a Recovery coefficients (RC) and b signal-to-noise ratios (SNR) for the four largest spheres for ${ }^{99 \mathrm{~m}} \mathrm{Tc}$ SPECT/CT and ${ }^{90} \mathrm{Y}$ BRS SPECT/CT and ${ }^{90} \mathrm{Y}$ PET/CT phantom measurements.

Table 2

Mean tumor and mean healthy liver absorbed dose estimates per patient from scaled ${ }^{99 \mathrm{~m}} \mathrm{Tc} /{ }^{90} \mathrm{Y}$ SPECT/CT, ${ }^{90} \mathrm{Y}$ BRS SPECT/CT and ${ }^{90} \mathrm{Y}$ PET/CT.

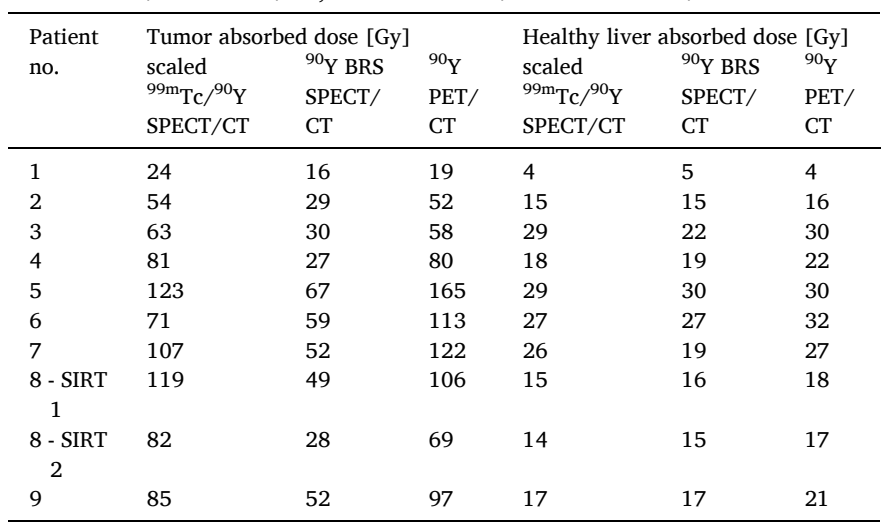

structures. The minimum absorbed dose that is at least received by $25 \%$, $50 \%$, and $75 \%$ of the tumor and healthy liver VOI volume is given by D25, D50, and D75 in Gy for scaled ${ }^{99 \mathrm{~m}} \mathrm{Tc} /{ }^{90} \mathrm{Y}$ SPECT/CT, ${ }^{90} \mathrm{Y}$ BRS SPECT/CT, and ${ }^{90} \mathrm{Y}$ PET/CT in Fig. $6 \mathrm{a}$ and $\mathrm{b}$ for tumor and liver respectively, averaged over the 10 investigated patient data sets.

\section{Discussion}

The availability of post-therapeutic ${ }^{90}$ Y SIRT dosimetry and the understanding of its strengths and limitations is advantageous to optimize treatment success by maximizing the absorbed dose delivered to the tumor while sparing healthy liver parenchyma. In combination with the retrospective analysis of existing patient data, post-therapeutic ${ }^{90} \mathrm{Y}$ SIRT dosimetry could become a valuable and substantial tool to further improve individual therapy outcome, especially if multiple therapy cycles are scheduled for the same patient. However, image based posttherapeutic ${ }^{90} \mathrm{Y}$ SIRT dosimetry is rarely implemented into clinical routine workflows, not least due to the differences in available imaging modalities in each center and a lack of consensus on standardized ${ }^{90} \mathrm{Y}$ SIRT dosimetry workflows. In the present work, we compared absorbed dose estimates for ten SIR-therapies in nine patients in dependence of the imaging modalities being involved, to mimic different technical equipment being available in SIRT-performing centers. We namely investigated post-therapeutic dose estimation by making use of the posttherapeutic ${ }^{90} \mathrm{Y}$ BRS SPECT/CT, of a combination of pre-therapeutic ${ }^{99 \mathrm{~m}} \mathrm{Tc}$-MAA SPECT/CT and post-therapeutic ${ }^{90} \mathrm{Y}$ BRS SPECT/CT, and of the post-therapeutic ${ }^{90} \mathrm{Y}$ PET/CT. The differences in absorbed doses in tumor and healthy liver based on the two SPECT/CT based methods were compared against those being derived from ${ }^{90} \mathrm{Y}$ PET/CT. Phantom measurements were included into this work in order to relate the observed absorbed dose estimation in patients to the quantification capabilities and limitations of the three imaging methods based on the patient imaging settings and reconstruction parameters used in this study.

When comparing the mean absorbed doses to healthy liver tissue, the ${ }^{90} \mathrm{Y}$ BRS SPECT/CT and the scaled ${ }^{99 \mathrm{~m}} \mathrm{Tc} /{ }^{90} \mathrm{Y}$ SPECT/CT based dosimetry showed only small deviations from ${ }^{90} \mathrm{Y}$ PET/CT dosimetry. A noticeable large overlap of absorbed doses estimated by the three methods was found, as documented in Fig. 5. This is underlined by similar mean differences and ranges in both Bland-Altman plots in Fig. 6. This finding is further confirmed by the observed high quantitative recovery of the large phantom background, which was $101 \%$ for ${ }^{90} \mathrm{Y}$ BRS SPECT/CT, $95 \%$ for ${ }^{99 \mathrm{~m}} \mathrm{Tc}$ SPECT/CT, and $96 \%$ for ${ }^{90} \mathrm{Y}$ PET/CT. However, regarding the minimal absorbed dose to $25 \%, 50 \%, 75 \%$ of the respective VOI volume (given by D25, D50, D75, Fig. 8 b), variations were found between the three methods. With respect to the discriminative recovery coefficients and noise characteristics, as assessed by the phantom measurements (see Fig. 2), these variations were likely caused by the differences in spatial resolution and quantification capability of the imaging methods.

Regarding the estimated absorbed doses to the tumors, a close agreement of $-2 \pm 18 \%$ averaged over all patients was observed between scaled ${ }^{99 \mathrm{~m}} \mathrm{Tc} /{ }^{90} \mathrm{Y}$ SPECT/CT and ${ }^{90} \mathrm{Y}$ PET/CT. Likewise, the D25, D50, and D75 for tumor absorbed doses in Fig. 8 a show a small deviation between scaled ${ }^{99 \mathrm{~m}} \mathrm{Tc} /{ }^{90} \mathrm{Y}$ SPECT/CT and ${ }^{90} \mathrm{Y}$ PET/CT. These findings have already been indicated by others, see Gnesin et al. [43] and Jadoul et al. [44] using a local deposition dosimetric approach, and Kafrouni et al. [35] and Richetta et al. [45] using a dose kernel approach, who all found a good comparability of ${ }^{99 \mathrm{~m}}$ Tc-MAA SPECT/CT based and ${ }^{90} \mathrm{Y}$ PET/CT based dosimetry in HCC. In addition to their approaches, we further included ${ }^{90} \mathrm{Y}$ BRS SPECT/CT based dosimetry to the comparison and observed a notable large underestimation of the tumor absorbed dose estimates of $-50 \pm 13 \%$ by ${ }^{90} \mathrm{Y}$ BRS SPECT/CT, 

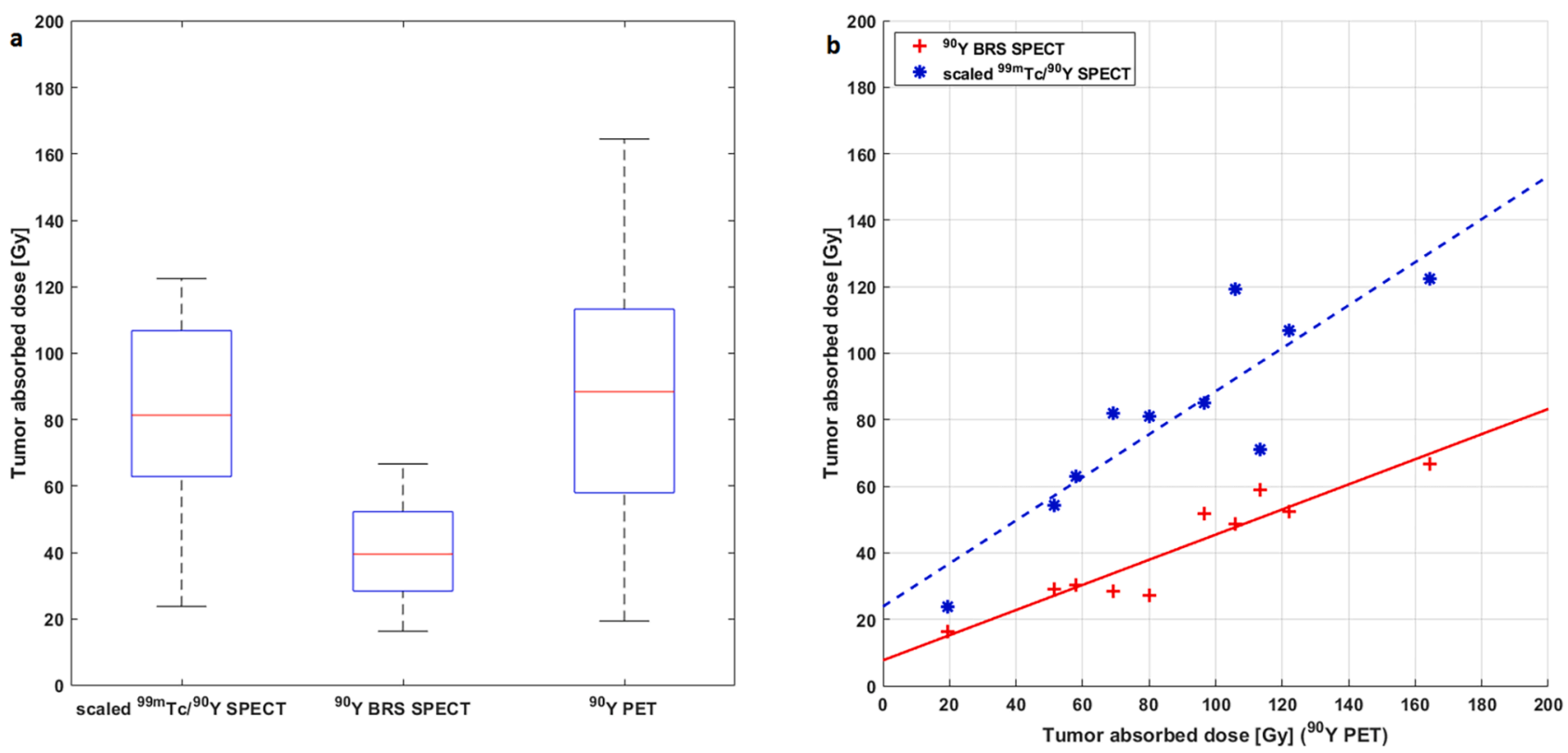

Fig. 3. a Boxplot of mean tumor absorbed doses obtained by scaled ${ }^{99 \mathrm{~m}} \mathrm{Tc} /{ }^{90} \mathrm{Y}$ SPECT/CT, ${ }^{90} \mathrm{Y}$ BRS SPECT/CT and ${ }^{90} \mathrm{Y}$ PET/CT, and b correlation plot of mean tumor absorbed doses of the two SPECT/CT based methods compared to ${ }^{90} \mathrm{Y}$ PET/CT.
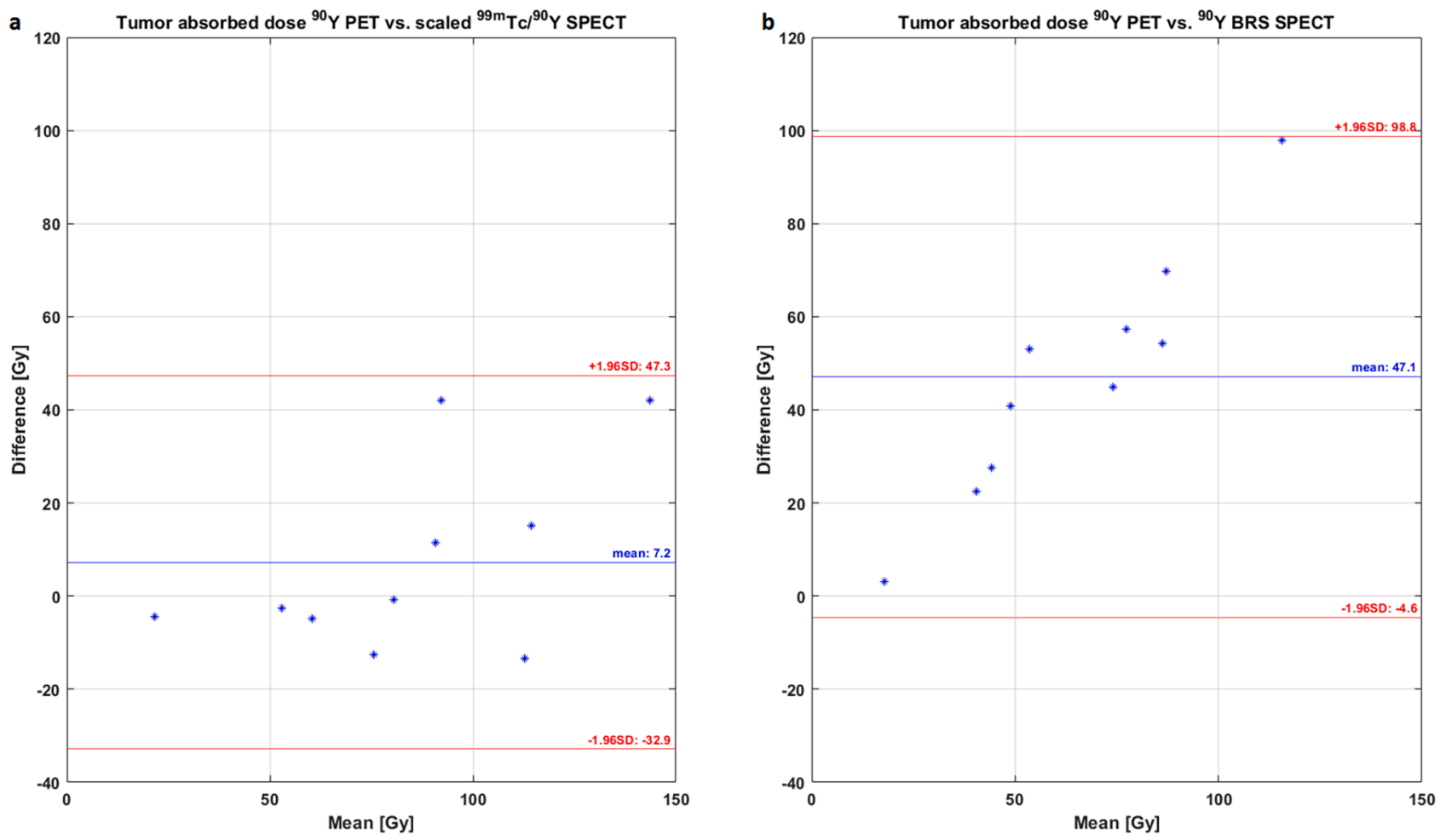

Fig. 4. Bland-Altman plots for tumor absorbed dose for a scaled ${ }^{99 \mathrm{~m}} \mathrm{Tc} /{ }^{90} \mathrm{Y}$ SPECT/CT compared to ${ }^{90} \mathrm{Y}$ PET/CT, and $\mathrm{b}{ }^{90} \mathrm{Y}$ BRS SPECT/CT compared to ${ }^{90} \mathrm{Y}$ PET/CT.

when compared to ${ }^{90} \mathrm{Y}$ PET/CT. This observation is further documented by the significantly reduced values for D25, D50 and D75 in Fig. 8 a, confirming the tendency found with the percentage deviations. The Bland-Altman analysis, shown in Fig. 4, revealed larger mean differences and a larger range of differences for the ${ }^{90} \mathrm{Y}$ BRS SPECT/CT dosimetry method compared to ${ }^{90} \mathrm{Y}$ PET/CT based dosimetry than for the scaled ${ }^{99 \mathrm{~m}} \mathrm{Tc} /{ }^{90} \mathrm{Y}$ SPECT/CT dosimetry approach compared to ${ }^{90} \mathrm{Y}$ $\mathrm{PET} / \mathrm{CT}$.

The exemplary patient absorbed dose images provided in Fig. 7 illustrate the good comparability of scaled ${ }^{99 \mathrm{~m}} \mathrm{Tc} /{ }^{90} \mathrm{Y}$ SPECT/CT (Fig. 7 b) and ${ }^{90} \mathrm{Y}$ PET/CT (Fig. 7 c), while the ${ }^{90} \mathrm{Y}$ BRS SPECT/CT (Fig. 7 a) based absorbed dose image expresses overall lower absorbed dose estimates. This observation can be explained by the highly limited capability of accurate activity quantification of ${ }^{90} \mathrm{Y}$ bremsstrahlung SPECT, as documented by the overall lower recovery coefficients in the spheres in Fig. 2 a. ${ }^{99 \mathrm{~m}} \mathrm{Tc}$ SPECT/CT and ${ }^{90} \mathrm{Y}$ PET/CT, in contrast, presented comparable quantification capabilities in our phantom measurements. It has to be considered, that the quantification capabilities (RCs and SNRs, 

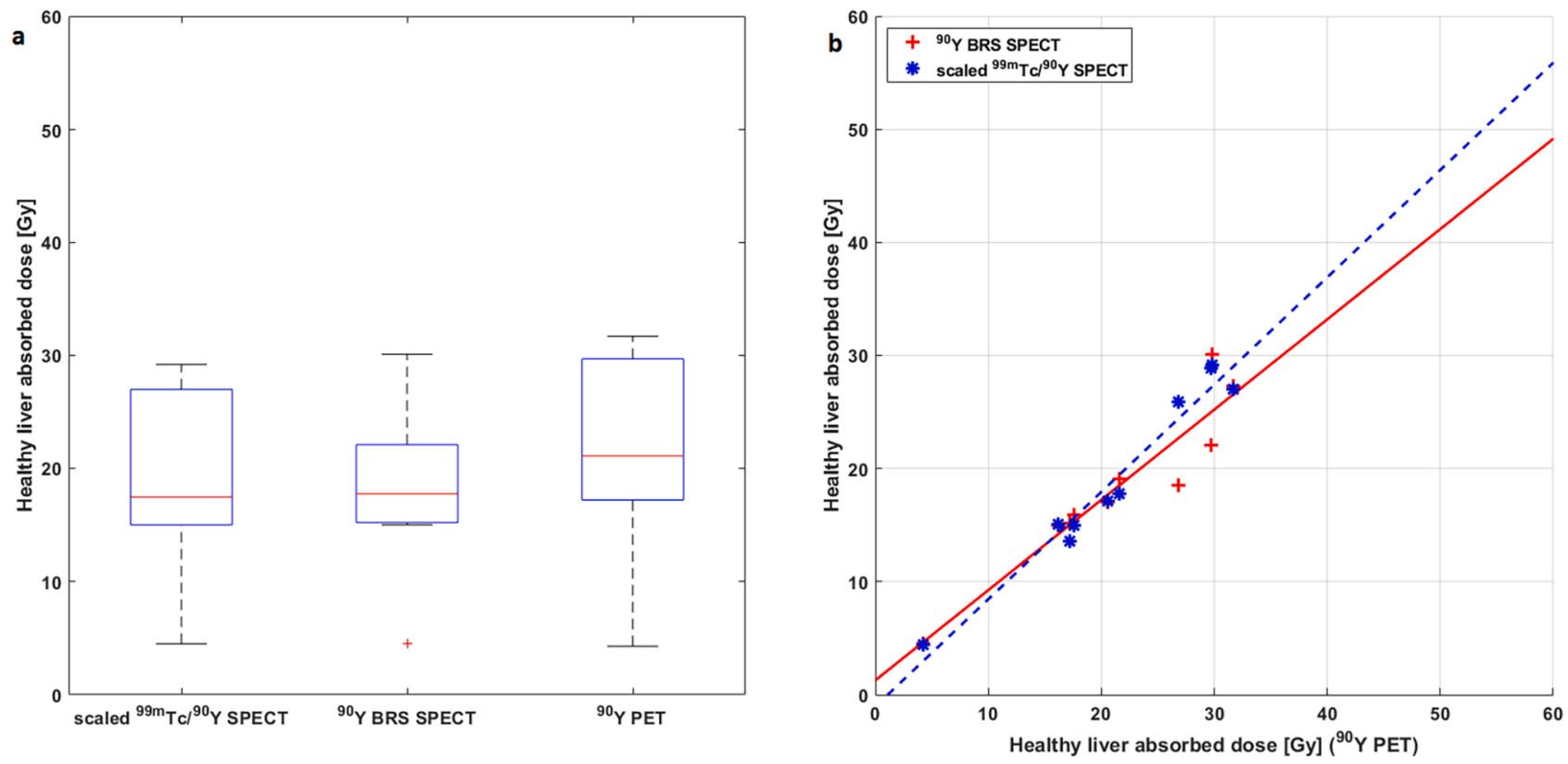

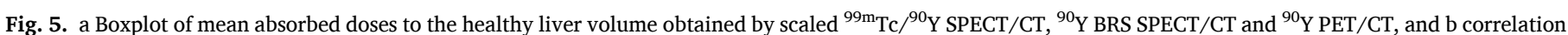
plot of mean absorbed doses to the healthy liver tissue of the two SPECT/CT based methods compared to ${ }^{90} \mathrm{Y}$ PET/CT.

see Fig. 2) of the three SIRT-related imaging methods presented in this study were derived from image data which were generated using the standard clinical routine imaging protocols and reconstruction parameters of our institution, without optimization for technical performance evaluations. Previously published studies analyzed ${ }^{90} \mathrm{Y}$ BRS SPECT/CT imaging protocols as well as ${ }^{90} \mathrm{Y}$ BRS SPECT/CT reconstruction [12,33,46-49] and provided recommendations for improved imaging and reconstruction parameters, which could have an impact on the

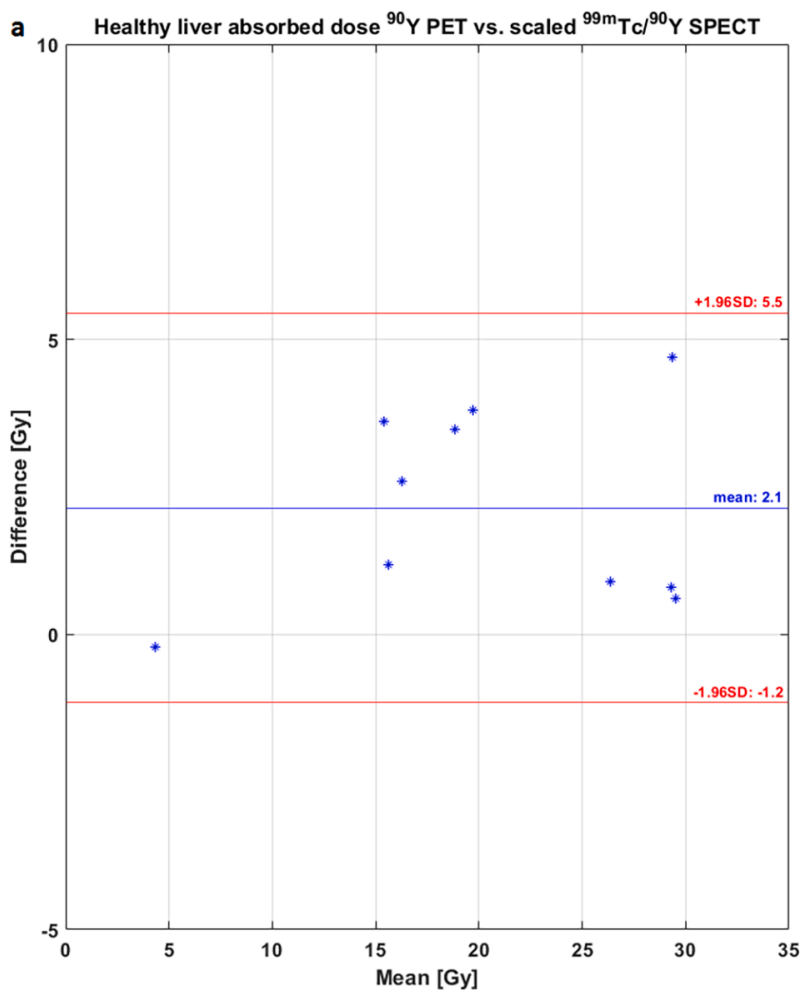

results presented here. However, the quantification capability of ${ }^{90} \mathrm{Y}$ BRS SPECT/CT is highly object-dependent and still below that of ${ }^{90} \mathrm{Y}$ PET/CT. Evidently, this is confirmed by the underestimation of all presented ${ }^{90} \mathrm{Y}$ BRS SPECT/CT based recovery coefficients and tumor absorbed dose estimates. Since ${ }^{90} \mathrm{Y}$ BRS SPECT/CT quantification capabilities are highly dependent on the image acquisition and reconstruction protocol and therefore may vary between individual treatment centers, this further complicates the comparability of absorbed dose

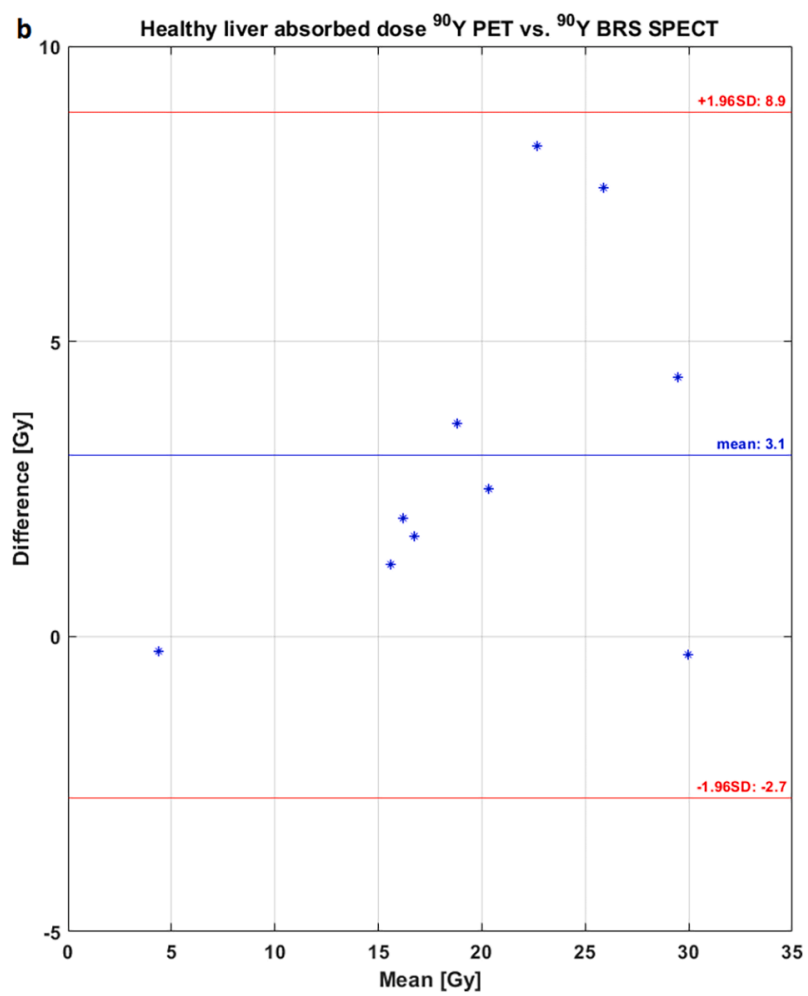

Fig. 6. Bland-Altman plots for healthy liver absorbed dose for a scaled ${ }^{99 \mathrm{~m}} \mathrm{Tc} /{ }^{90} \mathrm{Y}$ SPECT/CT compared to ${ }^{90} \mathrm{Y}$ PET/CT, and b ${ }^{90} \mathrm{Y}$ BRS SPECT/CT compared to ${ }^{90} \mathrm{Y}$ PET/CT. 


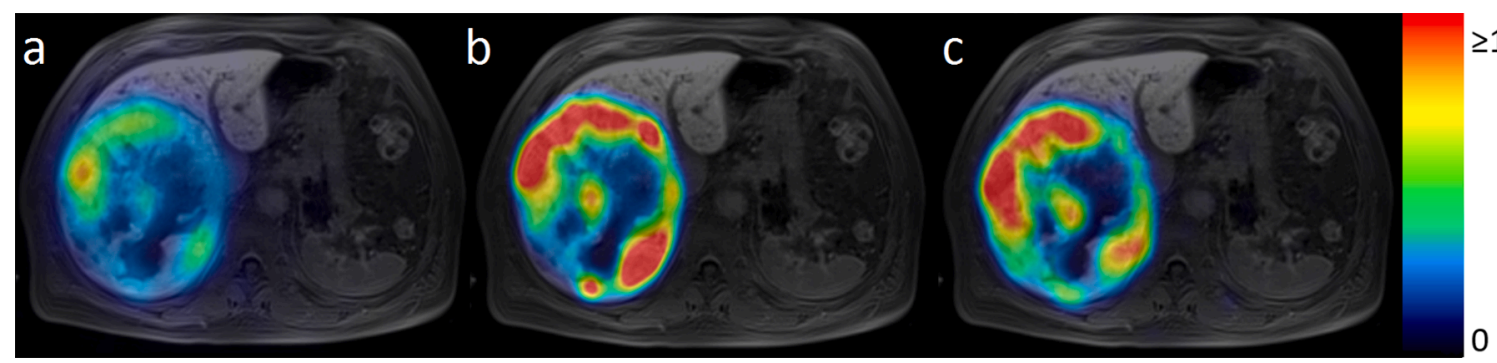

Fig. 7. Absorbed dose images of a ${ }^{90} \mathrm{Y}$ BRS SPECT/CT, b scaled ${ }^{99 \mathrm{~m}} \mathrm{Tc} /{ }^{90} \mathrm{Y}$ SPECT/CT, c ${ }^{90} \mathrm{Y}$ PET/CT for patient 2.

estimates obtained from ${ }^{90} \mathrm{Y}$ BRS SPECT/CT. On the other hand, the feasibility of ${ }^{90} \mathrm{Y}$ PET/CT based dosimetry, despite the inherent problem of a low count rate when imaging ${ }^{90} \mathrm{Y}$ with PET, has been proven by several studies $[9,50,51]$. Concordantly, we deduce that ${ }^{90} \mathrm{Y}$ SIRT dosimetry based on post-therapeutic ${ }^{90} \mathrm{Y}$ PET/CT is preferable, as indicated by Gates et al. [52] and Kao et al. [53], due to its superior quantification capabilities. In cases, where ${ }^{90} \mathrm{Y}$ PET/CT is clinically unavailable, and under the assumption that the pre- and posttherapeutic uptake patterns have a high degree of similarity, the use of the scaled ${ }^{99 \mathrm{~m}} \mathrm{Tc} /{ }^{90} \mathrm{Y}$ SPECT/CT could be a possible alternative for post-therapeutic absorbed dose estimation.

${ }^{99 \mathrm{~m}}$ Tc-MAA SPECT/CT based dosimetry is clearly restricted by the assumption that the distributions of pre-therapeutic ${ }^{99 \mathrm{~m}} \mathrm{Tc}-\mathrm{MAA}$ and therapeutic ${ }^{90} \mathrm{Y}$ microspheres are similar. However, there are differences in particle sizes, the amount of injected particles and the flow characteristics between ${ }^{99 \mathrm{~m}} \mathrm{Tc}-\mathrm{MAA}$ and ${ }^{90} \mathrm{Y}$ microspheres. Furthermore, the uptake of ${ }^{99 \mathrm{~m}} \mathrm{Tc}-\mathrm{MAA}$ depends on the tumor entity [54] and tumor vascularization. In this context, it is important to note that HCC, on which this study is focused, is a hypervascularized tumor. Thus, the results and conclusions do not necessarily apply to hypovascularized tumor entities. The use of ${ }^{99}$ Tc-MAA SPECT/CT for dosimetry for different tumor entities is a highly controversial topic with publications demonstrating or disproving a comparability of ${ }^{99 \mathrm{~m}} \mathrm{Tc}-\mathrm{MAA}$ and ${ }^{90} \mathrm{Y}$ microsphere distribution for either glass [55-58], or resin microspheres [25-27]. Consequently, post-therapeutic dosimetry should be performed cautiously when being based on a pre-therapeutic ${ }^{99} \mathrm{~m}$ Tc-MAA SPECT/CT. Yet, for the small number of evaluated patient cases included in our study, we observed a good concordance of pre- and posttherapeutic uptake patterns.

Recently, commercially available software including dose kernel dosimetry approaches similar to the one used in our investigations have been tested by Kafrouni et al. [35] and validated by Maughan et al. [59] for ${ }^{90} \mathrm{Y}$ SIRT with ${ }^{90} \mathrm{Y}$ PET/CT. This enables a broader application in clinical routine. However, the large deviations in absorbed dose values observed in our investigation suggest that not only the selected dosimetric concept [28], but also the choice of imaging method needs to be considered to facilitate reliable and comparable dosimetry.

Due to the fact, that this work is a retrospective patient study, the number of available patient data is limited. The acquisition of two posttherapeutic images $\left({ }^{90} \mathrm{Y}\right.$ BRS SPECT/CT and ${ }^{90} \mathrm{Y}$ PET/CT) is outside of clinical routine. This procedure leads to significantly increased patient discomfort and was therefore only performed if deemed valuable by the treating physician. Nonetheless, this investigation aimed in comparing post-therapeutic 3D absorbed dose images and absorbed dose estimates for tumors and healthy liver tissue using ${ }^{99 \mathrm{~m}} \mathrm{Tc}-\mathrm{MAA}$ SPECT/CT and ${ }^{90} \mathrm{Y}$ BRS SPECT/CT in comparison to ${ }^{90} \mathrm{Y}$ PET/CT. For this purpose, patients
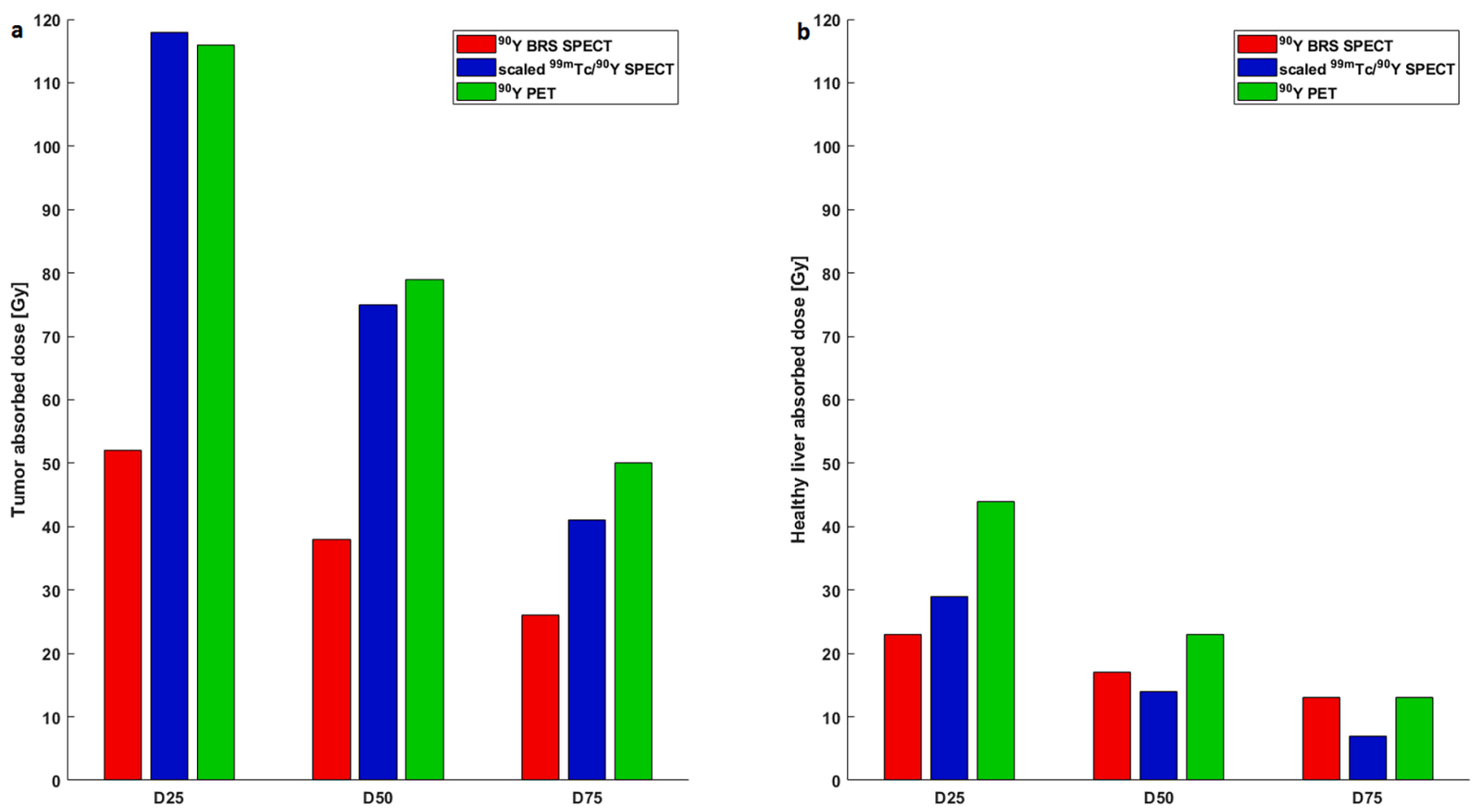

Fig. 8. Minimum absorbed doses to $25 \%, 50 \%$, and $75 \%$ (given by D25, D50, D75) of a the tumor volume and b the healthy liver volume for $\mathrm{scaled}^{99 \mathrm{~m}} \mathrm{Tc} /{ }^{90} \mathrm{Y}$ SPECT/CT, ${ }^{90} \mathrm{Y}$ BRS SPECT/CT and ${ }^{90} \mathrm{Y}$ PET/CT, averaged over all 10 patient data sets. D25, D50, and D75 represent the absorbed doses that are at least received in $25 \%, 50 \%$, and $75 \%$ of the related VOI volume. 
suffering from HCC receiving SIRT were retrospectively analyzed with the inclusion criteria of having both, post-therapeutic ${ }^{90} \mathrm{Y}$ BRS SPECT/ $\mathrm{CT}$ and ${ }^{90} \mathrm{Y}$ PET/CT. Consequently, the comparison of absorbed dose estimates as shown in the present work necessitate additional investigation in a larger cohort. However, this work was able to provide an initial analysis of absorbed dose estimates for a homogeneous set of HCC patients and is unique in combining post-therapeutic absorbed dose estimation based on scaled ${ }^{99 \mathrm{~m}} \mathrm{Tc} /{ }^{90} \mathrm{Y}$ SPECT/CT, ${ }^{90} \mathrm{Y}$ BRS SPECT/CT and ${ }^{90} \mathrm{Y} \mathrm{PET} / \mathrm{CT}$ in the same patient. The accompanying phantom studies further support our results, and enable comprehensible conclusions. Nevertheless, it is highly desirable to pursue this investigation with larger patient cohorts and to possibly further include other liver tumors than HCC.

\section{Conclusion}

For the post-therapeutic assessment of ${ }^{90} \mathrm{Y}$ SIRT dose estimates, the proposed scaled ${ }^{99 \mathrm{~m}} \mathrm{Tc} /{ }^{90} \mathrm{Y}$ SPECT/CT dosimetric approach showed the potential to reliably provide tumor absorbed dose estimates when compared to absorbed dose estimates obtained from ${ }^{90} \mathrm{Y}$ PET/CT, for given equivalence of tumor uptake pattern of ${ }^{99 \mathrm{~m}} \mathrm{Tc}-\mathrm{MAA}$ and ${ }^{90} \mathrm{Y}$ microspheres on SPECT/CT images. If this requirement is fulfilled, scaled ${ }^{99 \mathrm{~m}} \mathrm{Tc} /{ }^{90} \mathrm{Y}$ SPECT/CT SIRT dosimetry could be of particular benefit for retrospective analysis of therapy outcome based on absorbed dose estimates. This may help to further correlate absorbed dose estimates with overall survival and tumor response for ${ }^{90} \mathrm{Y}$ SIRT of existing patient data with no ${ }^{90} \mathrm{Y}$ PET/CT. Tumor absorbed dose estimates from ${ }^{90} \mathrm{Y}$ BRS SPECT/CT exhibited large dose underestimations when compared to ${ }^{90} \mathrm{Y}$ PET/CT. For healthy liver tissue, all three imaging methods provided comparable absorbed dose estimates. This initial comparison of posttherapeutic absorbed dose estimates in dependence of the imaging method based on ten SIRTs of patients suffering from HCC together with phantom measurements may support subsequent investigations with larger patient cohorts and multiple centers.

\section{Declaration}

\subsection{Ethics approval and consent to participate}

This study is based on retrospective and anonymised data, which was acquired for clinical dosimetry (Ethics Committee of LMU Munich).

\subsection{Consent for publication}

Not applicable.

\subsection{Availability of data and material}

Please contact author for data requests.

\section{Funding}

This work was partly funded by the German Research Foundation (DFG) within the Research Training Group GRK 2274, and partly supported by the funding program "Medizintechnik Bayern" of "Bayerisches Ministerium für Wirtschaft" for the DosePlan project, MED-1703-0005.

\section{Authors' contributions}

JB, AG, LK, MS, JR, JZ, PB, SZ, HI, AT and GB designed the concept of the study. JB, AG, AT and $\mathrm{HI}$ reviewed the clinical data for dosimetry. JB, AG, AT, HI and GB carried out all data analysis. All authors contributed to the drafting of the manuscript, and all authors read and approved the manuscript.

\section{Declaration of Competing Interest}

The authors declare that they have no known competing financial interests or personal relationships that could have appeared to influence the work reported in this paper.

\section{Acknowledgements}

Not applicable.

\section{References}

[1] Braat AJ, Smits ML, Braat MN, van den Hoven AF, Prince JF, de Jong HW, et al. (9) (0)Y Hepatic Radioembolization: An Update on Current Practice and Recent Developments. J Nucl Med. 2015;56(7):1079-87.

[2] Kennedy A, Nag S, Salem R, Murthy R, McEwan AJ, Nutting C, et al. Recommendations for radioembolization of hepatic malignancies using yttrium-90 microsphere brachytherapy: a consensus panel report from the radioembolization brachytherapy oncology consortium. Int J Radiat Oncol Biol Phys. 2007;68(1): 13-23.

[3] Gleisner KS, Spezi E, Solny P, Gabina PM, Cicone F, Stokke C, et al. Variations in the practice of molecular radiotherapy and implementation of dosimetry: results from a European survey. EJNMMI physics. 2017;4(1):28.

[4] European Commission. Council Directive 2013/59/Euratom of 5 December 2013 laying down basic safety standards for protection against the dangers arising from exposure to ionising radiation, and repealing Directives 89/618/Euratom, 90/641/ Euratom, 96/29/Euratom, 97/43/Euratom and 2003/122/Euratom. Official Journal of the European Union. 2014.

[5] Dezarn WA, Cessna JT, DeWerd LA, Feng W, Gates VL, Halama J, et al. Recommendations of the American Association of Physicists in Medicine on dosimetry, imaging, and quality assurance procedures for $90 \mathrm{Y}$ microsphere brachytherapy in the treatment of hepatic malignancies. 2011;38(8):4824-45.

[6] Levillain H, Derijckere ID, Marin G, Guiot T, Vouche M, Reynaert N, et al. 90 Y$\mathrm{PET} / \mathrm{CT}$-based dosimetry after selective internal radiation therapy predicts outcome in patients with liver metastases from colorectal cancer. 2018;8(1):60.

[7] O'Doherty JJJodiit. A review of 3D image-based dosimetry, technical considerations and emerging perspectives in 90Y microsphere therapy. 2015;2(2): 1.

[8] Selwyn RG, Nickles RJ, Thomadsen BR, DeWerd LA, Micka JA. A new internal pair production branching ratio of $90 \mathrm{Y}$ : the development of a non-destructive assay for 90Y and 90Sr. Appl Radiat Isot. 2007;65(3):318-27.

[9] Lhommel R, van Elmbt L, Goffette P, Van den Eynde M, Jamar F, Pauwels S, et al. Feasibility of $90 \mathrm{Y}$ TOF PET-based dosimetry in liver metastasis therapy using SIRSpheres. Eur J Nucl Med Mol Imaging. 2010;37(9):1654-62.

[10] Willowson KP, Tapner M, Team QL, Bailey DL. A multicentre comparison of quantitative (90)Y PET/CT for dosimetric purposes after radioembolization with resin microspheres: The QUEST Phantom Study. Eur J Nucl Med Mol Imaging. 2015;42(8):1202-22.

[11] Rong X, Du Y, Ljungberg M, Rault E, Vandenberghe S, Frey EC. Development and evaluation of an improved quantitative (90)Y bremsstrahlung SPECT method. Med Phys. 2012;39(5):2346-58.

[12] Elschot M, Lam MG, van den Bosch MA, Viergever MA, de Jong HW. Quantitative Monte Carlo-based 90Y SPECT reconstruction. J Nucl Med. 2013;54(9):1557-63.

[13] Yue J, Mauxion T, Reyes DK, Lodge MA, Hobbs RF, Rong X, et al. Comparison of quantitative Y-90 SPECT and non-time-of-flight PET imaging in post-therapy radioembolization of liver cancer. Med Phys. 2016;43(10):5779.

[14] Elschot M, Vermolen BJ, Lam MG, de Keizer B, van den Bosch MA, de Jong HW. Quantitative comparison of PET and Bremsstrahlung SPECT for imaging the in vivo yttrium-90 microsphere distribution after liver radioembolization. PLOS ONE 2013; 8(2):e55742

[15] Kim SP, Cohalan C, Kopek N, Enger SA. A guide to 90Y radioembolization and its dosimetry. Physica Med 2019;68:132-45.

[16] Ho S, Lau WY, Leung TW, Chan M, Ngar YK, Johnson PJ, et al. Partition model for estimating radiation doses from yttrium-90 microspheres in treating hepatic tumours. Eur J Nucl Med. 1996;23(8):947-52.

[17] Kao YH, Tan EH, Ng CE, Goh SW. Clinical implications of the body surface area method versus partition model dosimetry for yttrium-90 radioembolization using resin microspheres: a technical review. Ann Nucl Med. 2011;25(7):455-61.

[18] Kao YH, Hock Tan AE, Burgmans MC, Irani FG, Khoo LS, Gong Lo RH, et al. Imageguided personalized predictive dosimetry by artery-specific SPECT/CT partition modeling for safe and effective $90 Y$ radioembolization. J Nucl Med. 2012;53(4): 559-66.

[19] S.A. Gulec G. Mesoloras Stabin MJJoNM. Dosimetric techniques in 90Y-microsphere therapy of liver cancer: the MIRD equations for dose calculations. 2006;47 (7):1209.

[20] Flamen P, Vanderlinden B, Delatte P, Ghanem G, Ameye L, Van Den Eynde M, et al. Multimodality imaging can predict the metabolic response of unresectable colorectal liver metastases to radioembolization therapy with Yttrium-90 labeled resin microspheres. Phys Med Biol. 2008;53(22):6591-603.

[21] Snyder W, Ford M, Warner G, Watson S. MIRD pamphlet no. 11. The Society of Nuclear Medicine, New York. 1975:92-3. 
[22] Sarfaraz M, Kennedy AS, Lodge MA, Li XA, Wu X, Yu CX. Radiation absorbed dose distribution in a patient treated with yttrium-90 microspheres for hepatocellular carcinoma. Med Phys. 2004;31(9):2449-53.

[23] Dieudonne A, Garin E, Laffont S, Rolland Y, Lebtahi R, Leguludec D, et al. Clinica feasibility of fast 3-dimensional dosimetry of the liver for treatment planning of hepatocellular carcinoma with 90Y-microspheres. J Nucl Med. 2011;52(12): 1930-7.

[24] Kennedy A, Dezarn W, Weiss AJJNMRT. Patient specific 3D image-based radiation dose estimates for $90 \mathrm{Y}$ microsphere hepatic radioembolization in metastatic tumors. 2011;2(111):1-8.

[25] Ulrich G, Dudeck O, Furth C, Ruf J, Grosser OS, Adolf D, et al. Predictive value of intratumoral $99 \mathrm{mTc}$-macroaggregated albumin uptake in patients with colorectal liver metastases scheduled for radioembolization with $90 \mathrm{Y}$-microspheres. J Nucl Med. 2013;54(4):516-22.

[26] Wondergem M, Smits ML, Elschot M, de Jong HW, Verkooijen HM, van den Bosch MA, et al. 99mTc-macroaggregated albumin poorly predicts the intrahepatic distribution of $90 \mathrm{Y}$ resin microspheres in hepatic radioembolization. J Nucl Med. 2013;54(8):1294-301.

[27] Knešaurek K, Machac J, Muzinic M, DaCosta M, Zhang Z, Heiba SJTicr, et al. Quantitative comparison of yttrium-90 (90 Y)-microspheres and technetium-99m ( $99 \mathrm{~m} \mathrm{Tc}$ )-macroaggregated albumin SPECT images for planning $90 \mathrm{Y}$ therapy of liver cancer. 2010;9(3):253-61.

[28] Mikell JK, Mahvash A, Siman W, Mourtada F, Kappadath SC. Comparing voxelbased absorbed dosimetry methods in tumors, liver, lung, and at the liver-lung interface for (90)Y microsphere selective internal radiation therapy. EJNMMI Phys 2015;2(1):16.

[29] Fourkal E, Veltchev I, Lin M, Koren S, Meyer J, Doss M, et al. 3D inpatient dose reconstruction from the PET-CT imaging of $90 \mathrm{Y}$ microspheres for metastatic cancer to the liver: feasibility study. Med Phys. 2013;40(8):081702.

[30] Pasciak AS, Bourgeois AC, Bradley YC. A Comparison of Techniques for (90)Y PET, CT Image-Based Dosimetry Following Radioembolization with Resin Microspheres. Front Oncol. 2014;4:121.

[31] Lassmann M, Preylowski V, Schlögl S, Schoenahl F, Jörg G, Samnick S, et al. Is the Image Quality of I-124-PET Impaired by an Automatic Correction of. Prompt Gammas? 2013.

[32] Delker A, Fendler WP, Kratochwil C, Brunegraf A, Gosewisch A, Gildehaus FJ, et al. Dosimetry for 177 Lu-DKFZ-PSMA-617: a new radiopharmaceutical for the treatment of metastatic prostate cancer. Eur J Nucl Med Mol Imaging 2016;43(1): $42-51$.

[33] Siman W, Mikell J, Kappadath S. Practical reconstruction protocol for quantitative 90Y bremsstrahlung SPECT/CT. Med Phys 2016;43(9):5093-103.

[34] Balagopal A, Kappadath SCJMp. Characterization of 90Y-SPECT/CT selfcalibration approaches on the quantification of voxel-level absorbed doses following 90Y-microsphere selective internal radiation therapy. 2018;45(2):87583.

[35] Kafrouni M, Allimant C, Fourcade M, Vauclin S, Guiu B, Mariano-Goulart D, et al Analysis of differences between 99m Tc-MAA SPECT-and 90 Y-microsphere PETbased dosimetry for hepatocellular carcinoma selective internal radiation therapy. 2019;9(1):62.

[36] Forwood N, Willowson KP, Tapner M, Bailey DL. Assessment of the relative contribution of volume and concentration changes in Yttrium-90 labelled resin microspheres on ionization chamber measurements. Australas Phys Eng Sci Med 2017;40(4):943-8.

[37] Kossert K, Bokeloh K, Ehlers M, Nähle O, Scheibe O, Schwarz U, et al. Comparison of $90 \mathrm{Y}$ activity measurements in nuclear medicine in Germany. 2016;109:247-9.

[38] Carlier T, Willowson KP, Fourkal E, Bailey DL, Doss M, Conti MJMp. 90Y-PET imaging: Exploring limitations and accuracy under conditions of low counts and high random fraction. 2015;42(7):4295-309.

[39] Kafrouni M, Allimant C, Fourcade M, Vauclin S, Delicque J, Ilonca A-D, et al. Retrospective voxel-based dosimetry for assessing the ability of the body-surfacearea model to predict delivered dose and radioembolization outcome. J Nucl Med 2018;59(8):1289-95.

[40] Gallio E, Richetta E, Finessi M, Stasi M, Pellerito RE, Bisi G, et al. Calculation of tumour and normal tissue biological effective dose in $90 \mathrm{Y}$ liver radioembolization with different dosimetric methods. Physica Med 2016;32(12):1738-44.
[41] Botta F, Mairani A, Battistoni G, Cremonesi M, Di Dia A, Fasso A, et al. Calculation of electron and isotopes dose point kernels with FLUKA Monte Carlo code for dosimetry in nuclear medicine therapy. Med Phys. 2011;38(7):3944-54.

[42] Bland JM, Altman D. Statistical methods for assessing agreement between two methods of clinical measurement. The lancet. 1986;327(8476):307-10.

[43] Gnesin S, Canetti L, Adib S, Cherbuin N, Silva Monteiro M, Bize P, et al. Partition Model-Based 99mTc-MAA SPECT/CT Predictive Dosimetry Compared with 90Y TOF PET/CT Posttreatment Dosimetry in Radioembolization of Hepatocellular Carcinoma: A Quantitative Agreement Comparison. J Nucl Med. 2016;57(11): $1672-8$.

[44] Jadoul A, Bernard C, Lovinfosse P, Gérard L, Lilet H, Cornet O, et al. Comparative dosimetry between $99 \mathrm{~m}$ Tc-MAA SPECT/CT and $90 \mathrm{Y}$ PET/CT in primary and metastatic liver tumors. 2019:1-10

[45] Richetta E, Pasquino M, Poli M, Cutaia C, Valero C, Tabone M, et al. PET-CT post therapy dosimetry in radioembolization with resin $90 \mathrm{Y}$ microspheres: Comparison with pre-treatment SPECT-CT 99mTc-MAA results. Physica Med 2019;64:16-23.

[46] Rong X, Du Y, Frey EC. A method for energy window optimization for quantitative tasks that includes the effects of model-mismatch on bias: application to Y-90 bremsstrahlung SPECT imaging. Phys Med Biol. 2012;57(12):3711-25.

[47] Rong X, Frey EC. A collimator optimization method for quantitative imaging: application to Y-90 bremsstrahlung SPECT. Med Phys. 2013;40(8):082504.

[48] Uribe CF, Esquinas PL, Gonzalez M, Celler A. Characteristics of Bremsstrahlung emissions of (177)Lu, (188)Re, and (90)Y for SPECT/CT quantification in radionuclide therapy. Phys Med. 2016;32(5):691-700.

[49] Pacilio M, Ferrari M, Chiesa C, Lorenzon L, Mira M, Botta F, et al. Impact of SPECT corrections on 3D-dosimetry for liver transarterial radioembolization using the patient relative calibration methodology. Med Phys. 2016;43(7):4053.

[50] D'Arienzo M, Chiaramida P, Chiacchiararelli L, Coniglio A, Cianni R, Salvatori R, et al. 90Y PET-based dosimetry after selective internal radiotherapy treatments. Nucl Med Commun. 2012;33(6):633-40.

[51] D’Arienzo M, Filippi L, Chiaramida P, Chiacchiararelli L, Cianni R, Salvatori R, et al. Absorbed dose to lesion and clinical outcome after liver radioembolization with 90Y microspheres: a case report of PET-based dosimetry. Ann Nucl Med. 2013;27(7):676-80.

[52] Gates VL, Esmail AA, Marshall K, Spies S, Salem R. Internal pair production of $90 \mathrm{Y}$ permits hepatic localization of microspheres using routine PET: proof of concept. J Nucl Med. 2011;52(1):72-6.

[53] Kao Y-H, Steinberg JD, Tay Y-S, Lim GK, Yan J, Townsend DW, et al. Postradioembolization yttrium-90 PET/CT-part 1: diagnostic reporting. EJNMMI research. 2013;3(1):56.

[54] Ilhan H, Goritschan A, Paprottka P, Jakobs TF, Fendler WP, Bartenstein P, et al. Systematic evaluation of tumoral 99mTc-MAA uptake using SPECT and SPECT/CT in 502 patients before 90Y radioembolization. J Nucl Med. 2015;56(3):333-8.

[55] Chiesa C, Mira M, Maccauro M, Romito R, Spreafico C, Sposito C, et al. A dosimetric treatment planning strategy in radioembolization of hepatocarcinoma with 90Y glass microspheres. Q J Nucl Med Mol Imaging. 2012;56(6):503-8.

[56] Chiesa C, Mira M, Maccauro M, Spreafico C, Romito R, Morosi C, et al. Radioembolization of hepatocarcinoma with (90)Y glass microspheres: development of an individualized treatment planning strategy based on dosimetry and radiobiology. Eur J Nucl Med Mol Imaging. 2015;42(11):1718-38.

[57] Chiesa C, Lambert B, Maccauro M, Ezziddin S, Ahmadzadehfar H, Dieudonne A, et al. Pretreatment Dosimetry in HCC Radioembolization with (90)Y Glass Microspheres Cannot Be Invalidated with a Bare Visual Evaluation of (99m)TcMAA Uptake of Colorectal Metastases Treated with Resin Microspheres. J Nucl Med. 2014;55(7):1215-6.

[58] Garin E, Lenoir L, Rolland Y, Edeline J, Mesbah H, Laffont S, et al. Dosimetry based on $99 \mathrm{mTc}$-macroaggregated albumin SPECT/CT accurately predicts tumor response and survival in hepatocellular carcinoma patients treated with $90 \mathrm{Y}$ loaded glass microspheres: preliminary results. J Nucl Med. 2012;53(2):255-63.

[59] Maughan NM, Garcia-Ramirez J, Arpidone M, Swallen A, Laforest R, Goddu SM et al. Validation of post-treatment PET-based dosimetry software for hepatic radioembolization of Yttrium-90 microspheres. Med Phys 2019;46(5):2394-402. 